\title{
Neonatal screening for congenital adrenal hyperplasia
}

\author{
Hetty J van der Kamp and Jan M Wit \\ Department of Paediatrics, Leiden University Medical Center, Leiden, The Netherlands \\ (Correspondence should be addressed to H J van der Kamp, Department of Paediatrics, H-3, Leiden University Medical Center, PO Box 9600, \\ 2300 RC Leiden, The Netherlands; Email: H.J.van_der_Kamp@LUMC.nl)
}

\begin{abstract}
Congenital adrenal hyperplasia $(\mathrm{CAH})$ is well suited for newborn screening, as it is a common and potentially fatal disease which can be easily diagnosed by a simple hormonal measurement in blood. Moreover, early recognition and treatment can prevent severe salt wasting, dehydration and death and shorten the time of male sex assignment in virilised females.

In screening programmes, $17 \alpha$-hydroxyprogesterone (17OHP) is measured in filter paper blood spots obtained by a heel puncture preferably between 2 and 4 days after birth. Three assay techniques are utilised for initial screening: radio-immunoassay (USA), enzyme-linked immunosorbent assay (Japan) and time-resolved fluoro-immunoassay (Europe). Preterm newborns have higher $170 \mathrm{HP}$ concentrations in serum than babies born at term. Therefore, cut-off levels are based on gestational age (in Japan and Europe) or on birth weight (in the USA). There is a considerable variation in cut-off levels from one programme to another. This is most likely due to the different antibodies and reagents used, varying thickness and density of filter paper used for sample collection and, most significantly, the characteristics of the reference population (in terms of birth weight and gestational age).

More than 30 million newborns have been screened. The prevalence of CAH in the USA and Europe is approximately 1:15000-16000, and slightly lower in Japan (1:19000). In general, severe salt wasting can be prevented, but there is a remarkable variation in the number of false-positives and false-negatives among the various programmes. Ongoing refinement of cut-off levels is needed to improve specificity and sensitivity.
\end{abstract}

European Journal of Endocrinology 151 U71-U75

\section{Introduction}

Congenital adrenal hyperplasia (CAH) is, in $95 \%$ of the patients, due to a 21-hydroxylation defect in the adrenal cortex. Biochemically, this results in low serum concentrations of aldosterone and cortisol and elevated $17 \alpha$-hydroxyprogesterone (17OHP) and androstenedione (Fig. 1). Clinically, early-onset classical CAH consists of two variants: the salt wasting (SW) form (75\%) and the non-salt wasting (NSW) form (25\%) (1). In affected individuals, salt wasting predisposes to 'adrenal crises' with dehydration, which become life-threatening in the first weeks of life (2). In NSW, no electrolyte disturbances are found.

Female newborns with classical CAH are virilised at birth, ranging from slight clitoromegaly to complete masculinisation. Male infants have no physical signs at birth, so they are particularly at risk for dehydration and death. Persistent weight loss may be the only sign (3).

Newborns with $\mathrm{CAH}$ can be detected by screening and this has now been implemented in many industrialised countries (1). In this paper the current status of neonatal screening for $\mathrm{CAH}$ will be reviewed.

\section{History of neonatal screening}

The report 'Principles of Early Disease Detection' by Wilson and Jungner (1968) is probably the most cited source of criteria for screening (4). In 1974, the criteria were revised by Frankenburg, who stated that screening carried out without knowledge and consideration might do more harm than good (5). Summarised, the criteria are: (I) the disease should be a serious health problem and early detection should have a positive impact on morbidity and mortality; (II) the condition should be relatively common (prevalence $>1: 15000$ ); (III) the screening test must distinguish normal from affected subjects; (IV) patients must be identified before diagnosis is clinically suspected; (V) diagnostic tests and treatment need to be available; and (VI) the costs of finding affected individuals should be economically balanced with the benefits.

In 1963 the first neonatal screening programme for phenylketonuria (PKU) was introduced followed by the implementation of screening for congenital hypothyroidism $(\mathrm{CH}) 11$ years later $(6,7)$. The screening for CAH was first performed in Alaska in $1977(8,9)$. 


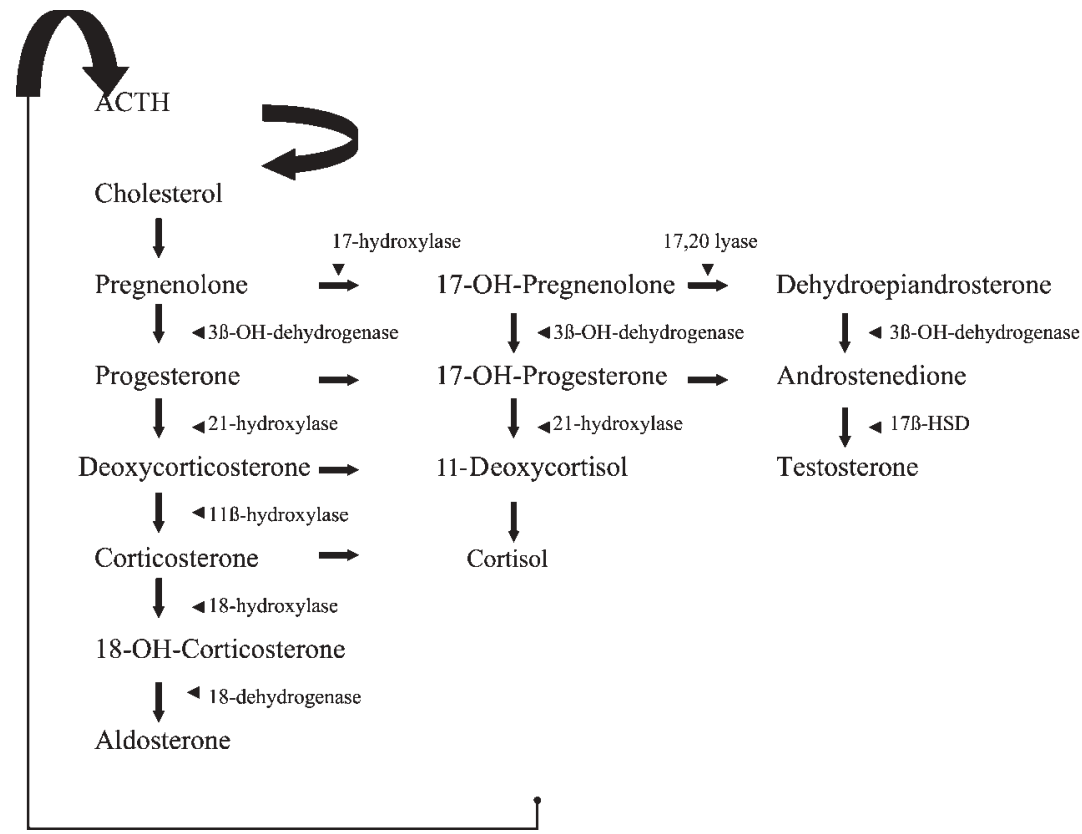

Figure 1 Scheme of adrenal steroidogenesis and the enzymes involved. $17 \beta-H S D, 17 \beta$-hydroxysteroid dehydrogenase.

A number of screening programmes for $\mathrm{CAH}$ have subsequently been developed worldwide. Health organisations in 13 countries (including the USA) perform newborn screening. Presently, more than 30 million newborns have been screened. The prevalence of $\mathrm{CAH}$ observed in the USA was 1:15981, in Japan 1:19111 and in Europe 1:14970 (10). The highest prevalence of $\mathrm{CAH}$ has been found in two geographically isolated populations, the Yupik Eskimos of Western Alaska (1:282) and the French island of La Réunion in the Indian Ocean (1:6071) (1).

\section{Benefits of screening on CAH}

$\mathrm{CAH}$ is a life threatening disorder, so it is expected that screening should improve survival rate. In fact, there is only indirect evidence for this: before screening an unequal sex ratio (female $>$ male) was observed in case surveys, while after the introduction of screening, equal numbers of males and females were found as expected for an autosomal recessive disorder. This indicates that before the introduction of screening some male babies must have died before the diagnosis was made. However, unfortunately death in the case of CAH still occurs (11).

The second goal of screening is the prevention of severe hyponatraemia and hyperkalaemia. Serum sodium dropped below $125 \mathrm{mmol} / \mathrm{l} 13$ days after birth in most salt wasting patients and severe hyperkalaemia $(>6.5 \mathrm{mmol} / \mathrm{l})$ was present in all patients from 11 days after birth (2). Besides the life-threatening short-term consequences, salt wasting may also have long-term effects, such as learning disabilities and behavioural problems $(12,13)$.
Shortening the period of incorrect sex assignment is the third benefit. Female newborns with classical $\mathrm{CAH}$ are virilised at birth, ranging from slight clitoromegaly to complete masculinisation. Strongly virilised females (Prader stage 4 and 5) may be falsely assigned to the male sex (14).

\section{Procedure and methods of screening}

The process of neonatal screening involves sampling, postal services, laboratory analysis, referral and diagnostic confirmation. The screening procedure must be rapid and efficient. The average age at which screening results are available in the various screening programmes is 7.6 days, with a range of 3-18 days (15).

At start, heel puncture blood samples are collected in term and preterm babies in the first week after birth. An increased 170HP concentration in heel puncture blood is used to indicate patients at risk of having $\mathrm{CAH}$ (Fig. 1). Sampling before 36 hours after birth will result in a high false-positive rate. However, sampling after days 5-7 reduces the screening benefit. The exact day of sampling and the following procedures depends on the local health care system. In the process of screening, postal services or transport of the dried blood spots is the most time consuming, taking on average 2.2 days (16).

For laboratory analysis, three assay techniques are utilised: radio-immunoassay (USA), enzyme-linked immunosorbent assay (Japan) and time-resolved fluoroimmunoassay (Europe). The 17OHP levels measured by direct fluoro-immunoassay are significantly higher than those measured by radioimmunoassay after 
extraction. The fluoro-immunoassay may overestimate $170 \mathrm{HP}$ levels in low birth weight infants weighing $<1500 \mathrm{~g}$ (17).

Although theoretically $17 \mathrm{OHP}$ concentrations in newborns should be comparable regardless of the assay method, there is considerable variation in cutoff levels from one programme to another. Cut-off levels that differentiate positive from negative screening test results have been established at greater than the 99th percentile of the mean level in healthy newborns. As preterms have higher 17OHP levels, cut-off levels are based on birth weight or on gestational age. In the USA, Canada and New Zealand, cut-off levels for CAH screening are based on birth weight, while in European countries and Japan gestational age is used to establish cut-off levels $(11,18-24)$.

After biochemical analysis, abnormal results are reported by the laboratories involved to a coordinator or institution responsible for the screening. The suspected newborn is traced and it is decided whether the child should have a second heel puncture or has to be referred to a paediatric endocrinologist immediately. This decision can be made on the basis of the information from the parents about the condition of the child (weight, alertness and ambiguity) and/or on the degree of elevation of the $170 \mathrm{HP}$ concentration (Fig. 2). If the child is considered as having a high risk of $\mathrm{CAH}$, it should be referred to a paediatric endocrinologist to confirm the diagnosis. Screening 17OHP assays are generally non-specific and cannot be compared with diagnostic serum levels.

\section{Results}

The European results of screening in $\mathrm{CAH}$ are shown in Table 1 (22-28). The reliability of each screening programme is based on the evaluation of both falsepositive (1-specificity) and false-negative (1-sensitivity) rates. In Sweden and Switzerland, the high specificity as determined by the choice of the cut-off levels increases the risk of a lower sensitivity $(22,23)$. Improvement of the positive predictive value without loss of sensitivity can be achieved by a second heel puncture in the case of borderline results (22). With age, serum 170HP levels decline in unaffected neonates but rise in classic $\mathrm{CAH}$ patients. Improvement of the specificity without loss of sensitivity can also be attained by additional procedures like organic extraction, chromatography or measuring the $17 \mathrm{OHP}-$ cortisol ratio. DNA analysis in heel puncture blood is not routinely in use as it is very expensive $(15,29)$.

Only two studies have been reported where an area with screening was compared with an area without screening. In an American retrospective cohort study, the results of screening in Texas were compared with the unscreened population of Arkansas and Oklahoma (30). The incidence of CAH was similar (1:15974 versus 1:17396). Diagnosis in males was made 2 weeks earlier in the screening area, but no data were reported about the severity of salt wasting in both groups. In The Netherlands a prospective study was performed, comparing the results of a screened and unscreened area (3). In the screened part of the country, therapy was started at the median age of 7 days and the mean (S.D.) serum sodium concentration was 134.5 (3.4) $\mathrm{mmol} / \mathrm{l}$. In the area without screening, therapy started at the median age of 14 days and the serum sodium was $124.5(10.8) \mathrm{mmol} / \mathrm{l}$.

Additional effects of the introduction of the neonatal screening are increased awareness and knowledge of $\mathrm{CAH}$ by health workers, the achievement of a consensus for treatment and the formation of a patients' association. Early detection of CAH patients by screening resulted in a reduction in hospitalisation (3).

\section{Pitfalls}

First, neonatal screening programmes cannot be passed from one country to the other without adaptations. For example, there is a considerable variation in cut-off

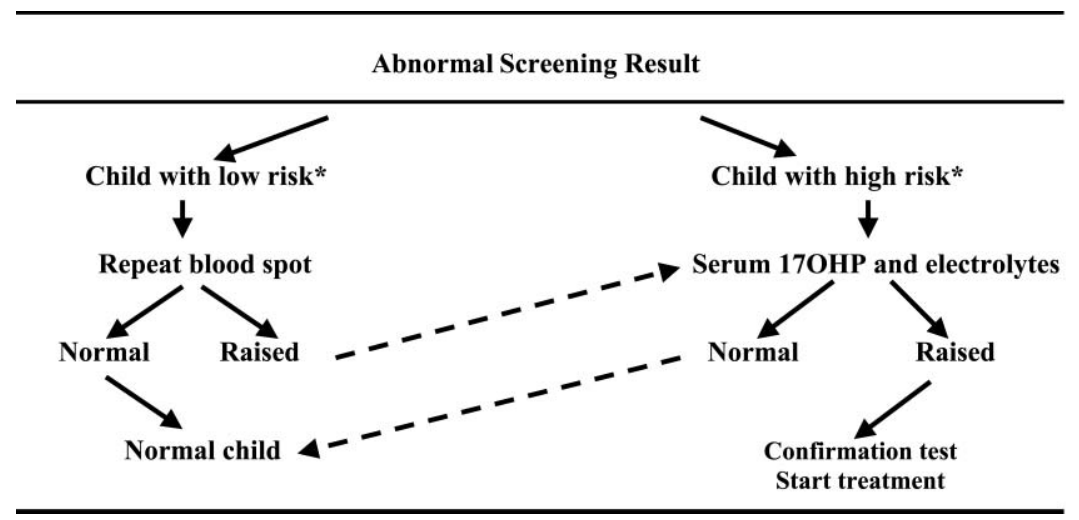

Figure 2 Adapted guidelines according to the European Society of Paediatric Endocrinology in the case of abnormal screening results (35). *Risk establishment is based on the 17OHP concentration in the blood spot and on the clinical condition of the child. 
Table 1 Overview of neonatal screening for $\mathrm{CAH}$ in some European countries.

\begin{tabular}{|c|c|c|c|c|c|c|}
\hline $\begin{array}{l}\text { Country } \\
\text { (reference) }\end{array}$ & $\begin{array}{l}\text { Publication } \\
\text { year }\end{array}$ & $\begin{array}{l}\text { Number } \\
\text { screened }\end{array}$ & Prevalence & $\begin{array}{l}\text { Specificity } \\
(\%)\end{array}$ & $\begin{array}{c}\text { Sensitivity } \\
(\%)\end{array}$ & $\begin{array}{c}\text { Positive predictive } \\
\text { value }(\%)\end{array}$ \\
\hline Beigium (25) & 1997 & 206,108 & $1: 25000$ & 99.10 & 100 & 0.43 \\
\hline Switzerland (22) & 2002 & 333,221 & $1: 10749$ & 99.99 & 97 & 50 \\
\hline France (26) & 1999 & 408,138 & $1: 11661$ & 99.62 & 97 & 2.1 \\
\hline Italy $(24)^{\star}$ & 1996 & 128,330 & $1: 11666$ & 99.66 & 91 & 2.3 \\
\hline Sweden (23) & 1992 & 557,410 & $1: 11612$ & 99.96 & 92 & 24.0 \\
\hline Netherlands $(27,28)$ & 2003 & 647,674 & $1: 14700$ & 99.95 & 100 & 11.4 \\
\hline
\end{tabular}

* In 1991-1995.

levels from one programme to another. This is most likely due to different assays, antibodies and reagents used, varying thickness and density of the filter paper used for sample collection, day of sampling and the characteristics of the reference population (particularly with regard to birth weight and gestational age).

Secondly, screening of $170 H P$ levels leads to a certain number of false-positives. Not only is there crossreaction by steroid sulphates and glucuronides in immunoassays that may alert the system, but also severe illness and dehydration can raise $170 \mathrm{OP}$ above the cut-off limit. Aside from unnecessary anxiety by the parents, a low predictive value bears the risk of trivialisation of screening results by health workers. This was also reported in screening for phenylketonuria and congenital hypothyroidism. However, one should remain aware of the fact that unrecognised $\mathrm{CAH}$ is, in contrast with PKU and $\mathrm{CH}$, a lethal disease.

Finally, corticosteroids during pregnancy and in the neonatal period may result in false-negatives by suppression of the neonatal adrenal function. Recently, a child with $\mathrm{CAH}$ was missed by $17 \mathrm{OHP}$ screening because of neonatal dexamethasone treatment. This underlines the need for a careful medical history if $\mathrm{CAH}$ is suspected, even if $17 \mathrm{OHP}$ was normal on screening (31).

\section{Costs}

In CAH screening, no data are available about a financial analysis of costs versus benefits. Only costs were determined and were approximately 45000 Euros per $\mathrm{CAH}$ patient detected in Europe and approximately $\$ 66000$ in Texas $(3,32,33)$. These costs did not include expenses for additional tests to confirm diagnosis. From these figures, and the regional prevalence, the costs per $\mathrm{CAH}$ patient detected can be calculated.

Cost-effectiveness in terms of morbidity is also difficult to calculate. One benefit of screening could be that the frequency of minor handicaps (learning disabilities and behavioural problems), reported in two retrospective studies in patients, might be decreased (12, 13). Another possible benefit is that the frequency of skin problems could be decreased by screening, according to a prospective study showing more skin problems at the age of two years in patients with severe salt wasting postnatally (34). Long-term follow up is necessary to investigate whether prevention of salt wasting will improve the outcome of patients with $\mathrm{CAH}$.

\section{Conclusions}

Newborn screening is dependent on close cooperation between health workers involved in sample collection, laboratory analysis, follow-up, diagnosis, treatment and evaluation. The prevalence above 1:15000 and the high specificity and sensitivity have allowed addition of $\mathrm{CAH}$ screening to the routinely performed newborn screening programme in many countries. Additional effects of implementation, like development of consensus for treatment and formation of a patients' association are also important. Early detection of $\mathrm{CAH}$ patients by screening resulted in a reduction in hospitalisation. In terms of costs effectiveness, there is no doubt that screening advances the age at diagnosis and thereby mitigates the clinical picture of the affected babies and reduces mortality. It is uncertain whether prevention of salt wasting will improve the outcome of patients with $\mathrm{CAH}$ in terms of reduction of morbidity in later childhood, adolescence and adulthood.

\section{References}

1 Pang S \& Shook MK. Current status of neonatal screening for congenital adrenal hyperplasia [see comments]. Current Opinion in Pediatrics $19979419-423$.

2 van der Kamp HJ \& Stikkelbroeck MML. Development of hyponatremia and hyperkalemia in neonates with congenital adrenal hyperplasia (21-hydroxylase deficiency). Hormone Research 2002 58 (Suppl 2) 1-198.

3 van der Kamp HJ, Noordam K, Elvers B, Van Baarle M, Otten BJ \& Verkerk PH. Newborn screening for congenital adrenal hyperplasia in the Netherlands. Pediatrics 2001108 1320-1324.

4 Wilson JMG \& Jungner G. Principles and practice of screening for disease. Public Health Papers No. 34. Geneva: World Health Organization, 1968.

5 Therrell BL. US newborn screening policy: dilemmas for the twenty-first century. Molecular Genetics and Metabolism 200174 $64-74$.

6 Guthrie R \& Susi A. A simple phenylalanine method for detecting phenylketonuria in large populations of newborn infants. Pediatrics 196332338. 
7 Dussault JH. Commentary. The anecdotal history of screening for congenital hypothyroidism. Journal of Clinical Endocrinology and Metabolism $1999 \mathbf{8 4} 4332-4334$.

8 Pang S, Hotchkiss J, Drash AL, Levine LS \& New MI. Microfilter paper method for 17 alpha-hydroxyprogesterone radioimmunoassay: its application for rapid screening for congenital adrenal hyperplasia. Journal of Clinical Endocrinology and Metabolism $1977451003-1008$.

9 Pang S, Murphey W, Levine LS, Spence DA, Leon A, La Franchi S, Surve AS \& New MI. A pilot newborn screening for congenital adrenal hyperplasia in Alaska. Journal of Clinical Endocrinology and Metabolism $1982 \mathbf{5 5} 413-420$.

10 Pang S. International Newborn Screening Collaborative Study on 21-hydroxylase deficiency. Pediatric Research $2003 \mathbf{5 3}$ $155 \mathrm{~A}-156 \mathrm{~A}$

11 Therrell BL Jr, Berenbaum SA, Manter-Kapanke V, Simmark J, Korman K, Prentice L, Gonzalez J \& Gum S. Results of screening 1.9 million Texas newborns for 21-hydroxylase-deficient congenital adrenal hyperplasia. Pediatrics 1998101 583-590.

12 Nass R \& Baker S. Learning disabilities in children with congenital adrenal hyperplasia. Journal of Child Neurology 19916 306-312.

13 Donaldson MD, Thomas PH, Love JG, Murray GD, McNinch AW \& Savage DC. Presentation, acute illness, and learning difficulties in salt wasting 21-hydroxylase deficiency. Archives of Disease in Childhood $1994 \mathbf{7 0} 214-218$.

14 Prader A. Der Genitalbefund beim Pseudohermaphroditismus femininus des kongenitalen adrenogenitalen Syndroms. Helvetica Paediatrica Acta $19543231-248$.

15 Pang S. Newborn screening for congenital adrenal hyperplasia. Pediatric Annals 200332 516-523.

16 van der Kamp HJ. Thesis/Dissertation. 2001.

17 Al Saedi S, Dean H, Dent W, Stockl E \& Cronin C. Screening for congenital adrenal hyperplasia: the Delfia Screening Test overestimates serum 17-hydroxyprogesterone in preterm infants. Pediatrics 199697 100-102.

18 Naruse H, Suzuki E, Irie M, Tsuji A, Takasugi N, Fukushi M, Matsuura N \& Shimozawa K. Neonatal screening for congenital adrenal hyperplasia in Japan. Annals of the New York Academy of Sciences $1985 \mathbf{4 5 8} 103-110$.

19 Thompson R, Seargeant L \& Winter JS. Screening for congenital adrenal hyperplasia: distribution of 17 alpha-hydroxyprogesterone concentrations in neonatal blood spot specimens [see comments]. Journal of Pediatrics 1989114 400-404.

20 Cutfield WS \& Webster D. Newborn screening for congenital adrenal hyperplasia in New Zealand. Journal of Pediatrics 1995126 $118-121$.

21 Allen DB, Hoffman GL, Fitzpatrick P, Laessig R, Maby S \& Slyper A. Improved precision of newborn screening for congenital adrenal hyperplasia using weight-adjusted criteria for 17-hydroxyprogesterone levels. Journal of Pediatrics 1997130 128-133.

22 Steigert M, Schoenle EJ, Biason-Lauber A \& Torresani T. High reliability of neonatal screening for congenital adrenal hyperplasia in Switzerland. Journal of Clinical Endocrinology and Metabolism $2002874106-4110$.
23 Larsson A, Thil'en A, Hagenfeldt L, Dobeln von U \& Guthenberg C. Screening of half a million Swedish newborn infants for congenital adrenal hyperplasia. Screening 19921 159-166.

24 Balsamo A, Cacciari E, Piazzi S, Cassio A. Bozza D, Pirazzoli P \& Zappella F. Congenital adrenal hyperplasia: neonatal mass screening compared with clinical diagnosis only in the Emilia-Romagna region of Italy, 1980-1995. Pediatrics $199698362-367$.

25 Eyskens, F. Screening for inborn errors of metabolism; the experience in the province of Antwerp PhD Thesis University of Antwerp, 1997.

26 Cartigny-Maciejewski M, Guilley N, Vanderbecken S, Gorde S, Stuckers C, Ponte C, Weill J, Farriaux JP \& Paux E. Neonatal screening of congenital adrenal hyperplasia due to 21-hydroxylase deficiency: Lille experience 1980-1996. Archives of Pediatrics $19996151-158$.

27 Stikkelbroeck MML, Van der Kamp HJ \& Van Baarle W. Neonatal screening op het adrenogenitaal syndroom. Pilotonderzoek en landelijke invoering 1998-2001. Bithoven: RIVM, 2002.

28 Lanting CI \& Verkerk PH. Evaluatie van de screening op AGS/CHT/PKU bij kinderen geboren in 2002. TNO Prevention and Health, Leiden.

29 Nordenstrom A, Thilen A, Hagenfeldt L, Larsson A \& Wedell A. Genotyping is a valuable diagnostic complement to neonatal screening for congenital adrenal hyperplasia due to steroid 21hydroxylase deficiency [see comments]. Journal of Clinical Endocrinology and Metabolism 199984 1505-1509.

30 Brosnan PG, Brosnan CA, Kemp SF, Domek DB, Jelley OH, Blackett PR \& Riley WJ. Effect of newborn screening for congenital adrenal hyperplasia. Archives of Pediatrics and Adolescent Medicine 1999 $1531272-1278$

31 Rohrer TR, Gassmann KF, Pavel ME \& Dorr HG. Pitfall of newborn screening for congenital adrenal hyperplasia due to 21-hydroxylase deficiency. Biology of the Neonate 200383 65-68.

32 Thil'en A, Nordenstrom A, Hagenfeldt L, Von Dobeln U, Gutherberg C \& Larsson A. Benefits of neonatal screening for congenital adrenal hyperplasia (21-hydroxylase deficiency) in Sweden. Pediatrics $1998101 \mathrm{E} 11$.

33 Brosnan CA, Brosnan P, Therrell BL, Slater CH, Swint JM, Anneyers JE \& Riley WJ. A comparative cost analysis of newborn screening for classic congenital adrenal hyperplasia in Texas. Public Health Reports 1998113 170-178.

34 van der Kamp HJ \& Koopman HM. Health related quality of life in 2-year-old children with congenital adrenal hyperplasia is not reduced. Hormone Research 200360 (Suppl 2) 78.

35 Honour JW. Procedure for neonatal screening for congenital adrenal hyperplasia due to 21-hydroxylase deficiency. Hormone Research 200155 201-205.

Received 18 May 2004

Accepted 5 August 2004 